\title{
Detection of Bacteriochlorophyll-containing Micro-organisms by Infrared Fluorescence Photomicrography
}

\author{
By BEVERLY K. PIERSON AND H. M. HOWARD \\ Department of Biology, University of Oregon, \\ Eugene, Oregon, 97403, U.S.A.
}

(Received I8 May 1972)

SUMMARY

Fluorescence in the near infrared of individual photosynthetic bacteria was photographed through the microscope with infrared sensitive film. The fluorescence was also observed directly with an infrared sensitive image converter.

\section{INTRODUCTION}

The principles of fluorescence microscopy have been applied previously to reveal the presence of chlorophyll $a$ in micro-organisms (Brock, I968). When algae are illuminated with blue exciting light, they are easily seen by their bright red fluorescence. This property has been used to confirm the identity of chlorophyll $a$-containing micro-organisms in mixed field collections of blue-green algae and heterotrophic bacteria from hot springs (Brock, 1968). In such collections it would also be desirable to identify the photosynthetic bacteria which may appear morphologically identical to blue-green algae and chemotrophic bacteria. Since photosynthetic bacteria contain bacteriochlorophylls that fluoresce in the near infrared, it is impossible to detect visually the fluorescence with standard light microscopy. This report describes the use of two techniques that permit detection of infrared bacteriochlorophyll fluorescence with microscopy. The first technique uses infraredsensitive film; the second uses an infrared image converter.

\section{METHODS}

Film technique. Purple photosynthetic bacteria containing bacteriochlorophyll $a$ show a fluorescence maximum in vivo at approximately $900 \mathrm{~nm}$ (Olson \& Stanton, I966). Eastman spectroscopic safety film type I-M* (Eastman Kodak Co., Rochester, New York, U.S.A.) is sensitive in this region (Fig. I). To increase sensitivity, the film was hypersensitized immediately before use at $6{ }^{\circ} \mathrm{C}$ in $1 \%$ ammonia for $3 \mathrm{~min}$ followed by immersion in $95 \%$ ethanol for $2.5 \mathrm{~min}$. The film was dried in a Kinderman rapid drier (Ehrenreich Photo-Optical Industries, New York, U.S.A.) and stored in metal cannisters before loading the camera. This treatment gave the film an exposure index of ASA (American Standards Association) 400, which is equivalent to the European Din 27, for bright field photomicrography. The film is so sensitive to visible and infrared radiation that it must be handled minimally and only in total darkness, stored below $0{ }^{\circ} \mathrm{C}$, and cannot be used in film loaders or stored in plastic cassettes without a high degree of fogging which results from infrared exposure.

* The film is available in $35 \mathrm{~mm}$ Ioo $\mathrm{ft}$ rolls and standard cut film sizes on estar base and as standard glass plates. 


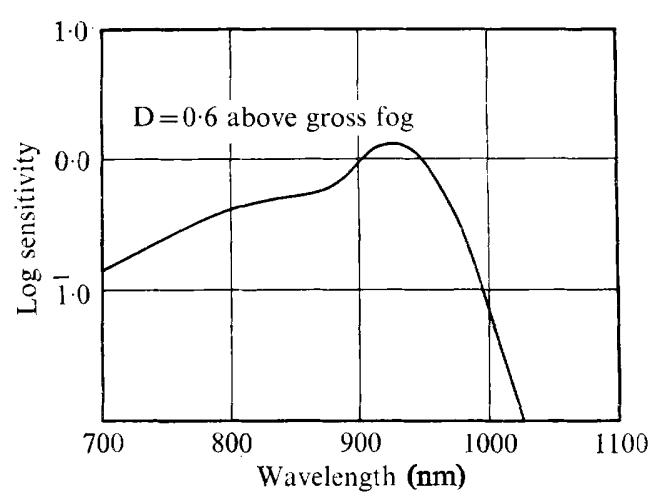

Fig. I. Spectrum of sensitivity of hypersensitized Eastman spectroscopic safety film type I-M. From Kodak Plates and Films for Science and Industry, p. I4d (Kodak Publication no. P-9, Eastman Kodak Co., Rochester, New York).

To record infrared fluorescence using this film, the bacteria to be examined were suspended in distilled water and dried on a microscope slide. The mount was placed on a Zeiss Universal microscope (Zeiss, Oberkochen, W. Germany) and was illuminated with a mercury arc lamp (HBO $200 \mathrm{~W} / 4$ ) (Osram, Berlin, W. Germany) with emission peaks at 334,365 to $366,405,435,546$ and 577 to $579 \mathrm{~nm}$. The exciting beam was passed through a standard Zeiss heat-absorbing filter, a Zeiss BG 38 red suppressor filter, $4 \mathrm{~mm}$ of Corning I-59 heat-absorbing filters (Corning Glass Works, Corning, New York, U.S.A.) and $8 \mathrm{~mm}$ of Corning $4-76$ infrared-absorbing filters, in that order. A $13 \%$ copper sulphate solution in water may be substituted for the Corning 4-76 filters (Eastman Kodak Co., I968). With the condenser focused for Köhler illumination and the condenser diaphragm open completely, the exciting beam had an intensity of $7.3 \times 10^{5} \mathrm{ergs} . \mathrm{cm}^{-2} . \mathrm{s}^{-1}$ at the bacterial layer, measured on a YSI-Kettering Model 65 radiometer (Yellow Springs Instrument Co., Yellow Springs, Ohio, U.S.A.). The exciting-filter system was used to remove the little infrared output from the mercury arc. The emission peaks of the mercury arc lamp fall within the absorption peaks of bacteriochlorophyll $a$ in purple bacteria (Olson \& Stanton, 1966). Absorption of the $546 \mathrm{~nm}$ light by carotenoids in the bacteria may also contribute to fluorescence from bacteriochlorophyll $a$.

For high apertures, 10, 25 and 40 power plan-apochromatic objectives were used. The barrier-filter system consisted of a Kodak Wratten no. $87 \mathrm{C}$ filter (Eastman Kodak Co.). This is a cut-off filter transmitting no radiation below $800 \mathrm{~nm}$ and having a transmittance of 70 to $80 \%$ in the range of 880 to $920 \mathrm{~nm}$. The filter was cut to fit the aperture in

Fig. 2. (a) Bright-field photomicrograph of dried cell masses of Rhodospirillum rubrum. (b) Infrared fluorescence photomicrograph of the same field at the same magnification as in $(a)$. Exposure time $15 \mathrm{~min}$. (c) Phase-contrast photomicrograph of dried cell masses and individual cells of $R$. rubrum. (d) Infrared fluorescence photomicrograph of the same field at the same magnification as in $(c)$. Exposure time $15 \mathrm{~min}$. (e) Infrared fluorescence photomicrograph of isolate $\mathrm{OH}-64-\mathrm{fl}$ Clone 5 filaments containing bacteriochlorophylls $a$ and $c$. Dried preparation. Exposure time $15 \mathrm{~min}$. $(f)$ Infrared fluorescence photomicrograph of isolate OK-70-fl filaments containing bacteriochlorophylls $a$ and $c$. Dried preparation. Exposure time $15 \mathrm{~min}$. $(g)$ Photomicrograph of visible image produced by Wild M 500 infrared converter unit from infrared fluorescence of the same organism as in (e). Dried preparation. Exposure time $4 \mathrm{~min}$. (h) Photomicrograph of visible image produced by Wild M 500 infrared converter unit from infrared fluorescence of bacteriochlorophyll $a$ containing, filaments embedded in agar. Exposure time $7 \mathrm{~min}$. 

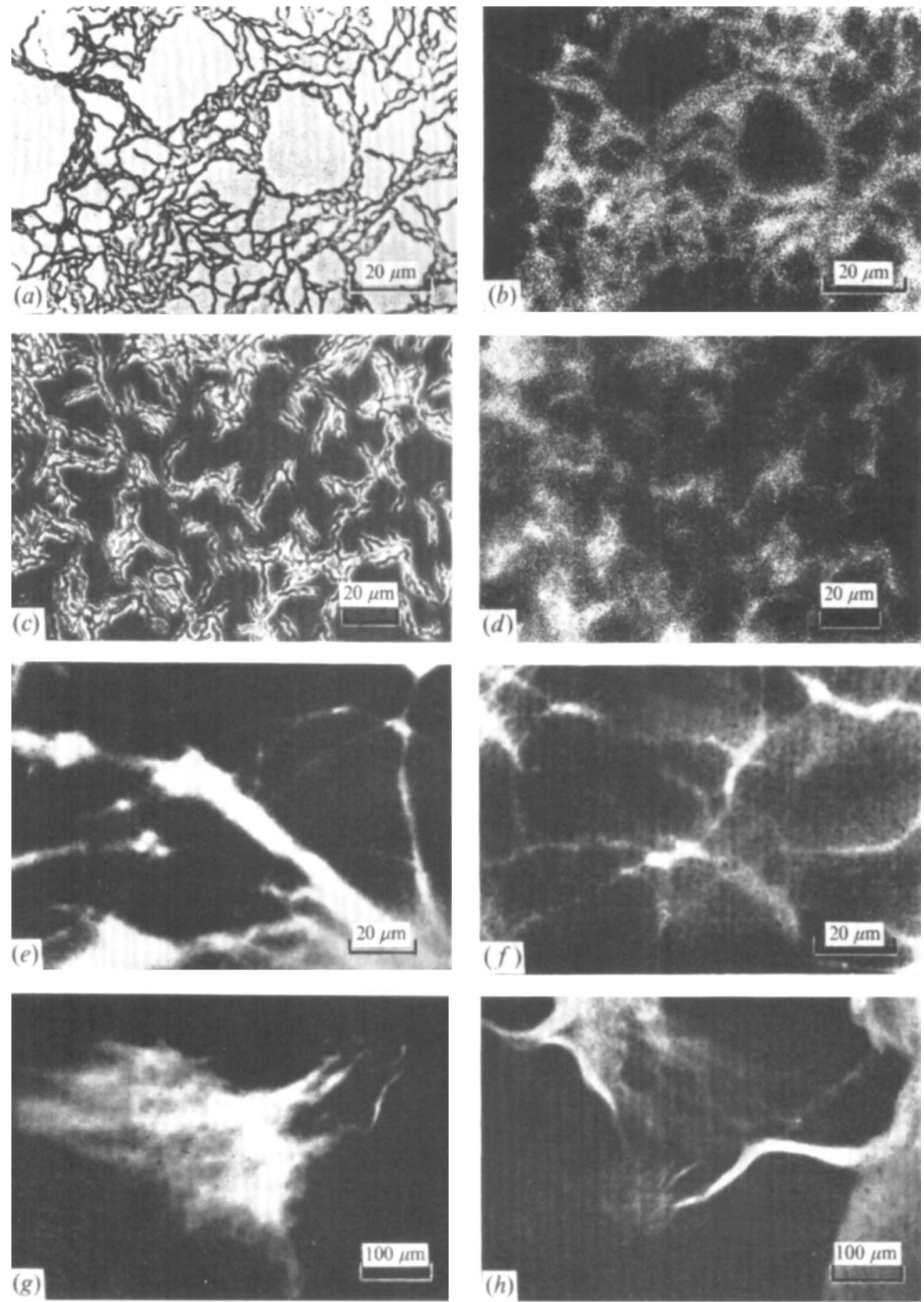
a Zeiss slider which fits into the microscope tube above the objectives. It was held in place in the slider with a snap ring to prevent edge diffraction. The film was loaded in a Nikon camera (Nikon, New York, U.S.A.) and exposures of 10 to $15 \mathrm{~min}$ were used to record the fluorescence image. When desired, a bright-field or phase-contrast picture of the same field could be taken on the same film by switching to a tungsten lamp and using an automatic camera box with an ASA setting of 400. In this way it was possible to photograph a mixed sample of organisms and to follow it with a fluorescence image of the same field to identify the cells producing infrared fluorescence. After exposure the film was developed in total darkness in D I9 developer (Eastman Kodak Co.) for $6 \mathrm{~min}$.

Image-converter technique. For this technique the Zeiss Universal microscope was used with a Wild M500 infrared image-converter unit (Wild Heerbrugg Ltd, Heerbrugg, Switzerland). The lamp, exciting-filter system, objectives and barrier filter were identical with those used in the film technique. The barrier filters provided with the Wild unit were not satisfactory for this work. The fluorescence image is converted by the Wild unit to a visible image seen through a special eyepiece focused on a fluorescent viewing screen. The same image was photographed in this case with Polaroid pack film (ASA 3000) (Polaroid Corporation, Cambridge, Massachusetts, U.S.A.) with exposure times of 2 to 7 min.

\section{RESULTS AND DISCUSSION}

Representative results from the infrared-sensitive film technique can be seen in Fig. $2 a-f$. Fig. 2(a)-(d) compares the fluorescence images from masses of Rhodospirillum rubrum with bright-field and phase-contrast photomicrographs of the same fields. Fig. $2(e)$ and $(f)$ are fluorescence images from two different isolates of the filamentous bacteria containing bacteriochlorophylls $a$ and $c$ described by Pierson \& Castenholz (197I). These Figures illustrate two of the problems of the infrared film technique - the large grain size which reduces clarity and the difficulty of achieving good focus when photographing infrared fluorescence images for long exposure periods. When the bacteriochlorophylls were extracted from all of the above organisms with methanol, no fluorescence images were detectable.

Fig. $2(g)$ and $(h)$ are photomicrographs of the visible images produced by the Wild infrared image-converter unit from the fluorescence of two different filamentous bacteria. The masses in Fig. $2(g)$ are the same organism illustrated in $2(e)$ with the film technique. The filament masses in $2(h)$ were living cells embedded in agar and not dried as in the other preparations. They are bacteriochlorophyll $a$-containing filaments described previously (Pierson \& Castenholz, 1971).

By using these techniques in association with visible fluorescence microscopy, morphologically similar organisms may be distinguished from each other. For example, the following taxonomically distinct organisms may be found together in a collection from a hot spring algal-bacterial mat: the blue-green alga Phormidium sp. (Brock, I968), the heterotrophic flexibacterium Herpetosiphon geysericola (Lewin, 1970), and the bacteriochlorophyll-containing filaments described by Pierson \& Castenholz (I97I). All are filamentous and range from 0.5 to $\mathrm{I} \cdot 5 \mu \mathrm{m}$ in diameter. All may appear orange in colour when collected en masse. Conventional visible fluorescence microscopy reveals characteristic red fluorescence only from the Phormidium containing chlorophyll $a$. Infrared fluorescence microscopy reveals fluorescence from the Phormidium and the bacteriochlorophyll-containing filaments. It is assumed that the infrared fluorescence detected beyond $800 \mathrm{~nm}$ from blue-green algae is due to a tailing fluorescence emission in this region. Published emission spectra that have been determined as far as 750 or $770 \mathrm{~nm}$ 
for some blue-green algae still show considerable emission at these wavelengths (Bergeron \& Olson, 1967; Brown, 1969). No fluorescence was revealed under any conditions from Herpetosiphon.

The advantage of the infrared film method is that it is relatively inexpensive and can be done on any microscope. The film is difficult to handle however, focusing is difficult, exposure times are long, and there is considerable delay between examining the cells and obtaining the results. The infrared image converter seems ideal for this work since the image can be focused, and the field examined quickly, producing immediate results.

We thank Wild Heerbrugg Instruments, for allowing us to use the Wild M500 unit while on demonstration at the University of Oregon. We thank Professor W. R. Sistrom for providing a culture of Rhodospirillum rubrum and for useful suggestions. We also thank Professor R. W. Castenholz for helpful discussion and the U.S. National Science Foundation for a grant to Professor Castenholz which helped support this work. We acknowledge support from a Health Science Advancement Award (FRO 6027) to the University of Oregon from the U.S. National Institutes of Health.

\section{REFERENCES}

Bergeron, J. A. \& Olson, J. M. (I967). Low-temperature fluorescence emission and excitation spectra for Anacystis nidulans. Biochimica et biophysica acta r31, $40 \mathrm{I}-404$.

Brock, T. D. (I968). Taxonomic confusion concerning certain filamentous blue-green algae. Journal of Phycology 4, 178-179.

Brown, J.S. (1969). Absorption and fluorescence of chlorophyll $a$ in particle fractions from different plants. Biophysical Journal 9, $1542-1552$.

Eastman Kodak Company. (1968). Applied Infrared Photography. A Kodak Technical Publication M-28, p. 75. Rochester, New York: Eastman Kodak.

Lewin, R. A. (1970). New Herpetosiphon species (Flexibacterales). Canadian Journal of Microbiology 16, $517-520$.

Olson, J. M. \& Stanton, E. K. (I966). Absorption and fluorescence spectra of bacterial chlorophylls in situ. In The Chlorophylls, pp. 381-398. New York: Academic Press.

Pierson, B. K. \& Castenholz, R. W. (I971). Bacteriochlorophylls in gliding filamentol. rokaryotes from hot springs. Nature New Biology 233, 25-27. 